\title{
ARIZONA study: is the risk of post-herpetic neuralgia and its burden increased in the most elderly patients?
}

\author{
Martin Duracinsky ${ }^{1,2^{*}}$, Marc Paccalin ${ }^{3}$, Gaëtan Gavazzi ${ }^{4}$, Sohéla El Kebir ${ }^{5}$, Jacques Gaillat ${ }^{6}$, Christophe Strady ${ }^{7}$, \\ Didier Bouhassira ${ }^{8,9}$ and Olivier Chassany ${ }^{1,10}$
}

\begin{abstract}
Background: In a context of change in the demographic profile of the older population, to identify an age threshold for increased risk and burden of herpes zoster ( $\mathrm{HZ})$ in $70+$ patients.

Methods: Post hoc analysis of the 12-month French nationwide prospective observational ARIZONA cohort study. $\mathrm{HZ}$ was assessed by means of the following validated questionnaires: Neuropathic Pain Symptom Inventory (NPSI), Zoster Brief Pain Inventory (ZBPI), Short-Form health survey (SF-12), and Hospital Anxiety and Depression Scale (HADS).

Results: 644 general practitioners included 1,358 volunteer patients with acute HZ in the ARIZONA study; 609 patients (45\%) were $70+$. In 70+ patients, age did not increase rash severity or HZ-related pain intensity at diagnosis, but increased by $64 \%$ the frequency of ophthalmic zoster (from $5.5 \%$ in $70-74$ years age-group to $9.0 \%$ in $85+$ patients, $p=N S$ ). Age was significantly associated with low physical health as assessed by the SF-12 Physical Component Summary (SF-12 PCS) score and bad mood as assessed by the HADS depression score $(p<0.001)$. Within the year following $\mathrm{HZ}$, post-herpetic neuralgia (PHN) was systematically but not significantly more frequent in $85+$ patients than in the $70-74,75-79$, or 80-84 years age-groups (19.0\% vs. $13.3 \% / 15.3 \% / 11.6 \%$ at month $3 ; 15.1 \%$ vs. $7.3 \% / 11.0 \% / 12.2 \%$ at month $6 ; 15.2 \%$ vs. $6.0 \% / 8.0 \%$ / $6.0 \%$ at month 12 , respectively). SF-12 PCS and HADS depression scores improved from day 0 to month 12 in all patients $(p<0.001) .85+$ patients were more impaired than younger patients $(p<0.001)$, but without clear difference according to PHN.

Conclusions: This study did not show in 70+ patients a clear and significant age threshold at which disease burden increased, although for some domains the impact seemed higher among the oldest patients; the cut-off of 70 years remains thus relevant for clinical and epidemiological studies. However, at individual level, assessment of the burden of $\mathrm{HZ}$ and $\mathrm{HZ}$-related pain appears necessary to improve management and prevent functional decline in the most vulnerable $70+$ patients.
\end{abstract}

Keywords: Elderly, Herpes zoster, Post-herpetic neuralgia, Neuropathic pain, Quality of life

\section{Background}

Herpes zoster (HZ) results from reactivation of varicellazoster virus (VZV) from a latent infection in the sensory ganglia [1,2]. HZ affects peripheral nerves and induces painful skin and nerve lesions. The acute phase is usually defined as $\leq 1$ month after rash onset, while post-herpetic

\footnotetext{
* Correspondence: duracinsky.m@gmail.com

'Paris-Diderot University Sorbonne Paris Cité, EA 7334 REMES,

Patient-Reported Outcomes Unit, 75010 Paris, France

${ }^{2}$ Internal Medicine and Clinical Immunology Department, AP-HP, Bicêtre

Hospital, 94275 Cedex Le Kremlin-Bicêtre, France

Full list of author information is available at the end of the article
}

neuralgia (PHN), the most common complication, is often defined as pain persisting for $\geq 3$ months after rash onset [3].

In part due to the decline of cell-mediated immunity with age, age is the major risk for developing both $\mathrm{HZ}$ and HZ-related pain, including PHN [4-7]. Previous studies suggested that $\mathrm{HZ}$ and PHN substantially impair health-related quality of life (HRQoL), that PHN may reduce the ability to maintain an independent lifestyle, and that acute and chronic HZ-related pain may impair activities of daily living, psychological well-being and social interactions [8-13]. The real long-term burden of illness 
experienced by $\mathrm{HZ}$ patients, and in particular by older patients, is not clearly known due to a lack of large-scale longitudinal studies [14]. Such data are needed with the expected increase in the number of people who will develop $\mathrm{HZ}$ and HZ-related pain [11-15].

ARIZONA is a large prospective longitudinal cohort study aiming to assess the real-life burden of $\mathrm{HZ}$ from the patient's perspective and the influence of age on disease burden. It was conducted in France in patients aged 50years or more $(50+)$ with acute $\mathrm{HZ}$ in the eruptive phase. Its main results have been recently published [16]. Multivariate analysis of ARIZONA results has shown that age $70+$ was an independent predictor of PHN at 3 months and that HZ-related pain, including PHN, impaired daily life functioning, HRQoL and mood. The age cut-off (70 years) was selected for consistency with the efficacy analysis of the Shingles Prevention Study, which compared the incidence of $\mathrm{HZ}$ and $\mathrm{PHN}$ in two groups receiving shingles (HZ) vaccine or placebo [17].

The world population is ageing. Moreover, the demographic profile of the older population is changing: the proportion of persons aged 80 or over $(80+)$ is projected to increase almost fourfold over the next 50 years [18]. In this context, to determine an age threshold at which $\mathrm{HZ}$ and PHN are particularly at risk for patients, including beyond 70 years of age could be helpful to improve patients' management.

The objective of this complementary analysis, performed on data from the most elderly ARIZONA patients (i.e., 70+ only), was thus to determine whether, beyond 70 years, age remained a risk factor for PHN and increased the burden of the disease, and whether a new age threshold could be defined in the most elderly patients.

\section{Methods}

The longitudinal prospective multicentre observational ARIZONA study was conducted in general practices in France between 20 November 2006 and 12 September 2008. The study, managed by a multidisciplinary scientific committee, was carried out in accordance with the principles of the Declaration of Helsinki (2004); approval was provided by an independent French review board (CCTIRS for Comité consultatif sur le traitement de l'information en matière de recherche). All patients provided written informed consent before enrolment. The study methods were published in detail in 2012 [16].

Briefly, 644 of the 29,177 general practitioners (GPs) randomly selected from the list of GPs practicing in France and contacted by post agreed to participate in the study and included at least one patient. Each GP included consecutively all $50+$ patients with acute $\mathrm{HZ}$ in the eruptive phase if (1) they were seen within 7 days of rash onset and (2) they had good understanding of French and telephone access. Eruptive phase was defined as visible skin lesions at any stage of development. Patients with HZ in the preceding 12 months or participating in any clinical trial were excluded. The study was managed by a multidisciplinary scientific committee. The protocol was approved by an Ethics Committee. All patients gave written informed consent.

At the inclusion consultation (day 0), the GP documented the subject's demographic and medical characteristics, HZ characteristics, and currently prescribed drugs. Rash severity was assessed by the GP based on quantitative and qualitative assessment of lesions.

The baseline questionnaire was to be completed by the patients at the GP's office during the recruitment consultation or at home within a day of the consultation. It comprised a dedicated form assessing the patient's perception of HZ-related pain and four validated self-reported questionnaires: the Neuropathic Pain Symptom Inventory (NPSI) [19]; the Zoster Brief Pain Inventory (ZBPI) [9,20]; the 12-item Short-Form health survey (SF-12) [21]; and the Hospital Anxiety and Depression Scale (HADS) [22].

The NPSI assesses the severity of each of the 10 symptoms of neuropathic pain on a scale ranging from 0 (no pain) to 10 (worst pain imaginable) [19]. On the global NPSI score, mild pain is defined by scores ranging between 0 and 29, moderate pain by scores ranging between 30 and 79 , and severe pain by scores ranging between 80 and 100. The ZBPI rates the severity of pain on a scale ranging from 0 (no pain) to 10 (pain as bad as you can imagine), and the interference of pain on the activities of daily life on a scale ranging from 0 (does not interfere) to 10 (completely interferes); mild interference is defined by scores ranging between 0 and 2, moderate interference by scores ranging between 3 and 4, and severe interference by scores ranging between 5 and $10[9,20]$. The Physical Component Summary (PCS) score and the Mental Component Summary (MCS) scores were calculated from the SF-12 [21]. SF-12 PCS or MCS scores $<50$ indicates HRQoL impairment (range score: 0-100). HADS anxiety or depression scores above 8 indicate anxiety or depression [22].

During the follow-up period (months 3, 6 and 12), patients were contacted by telephone and completed a follow-up questionnaire with the help of a trained interviewer, comprising the same dedicated form and questionnaires. PHN was defined as the persistence of pain of any intensity 3 months or more after the rash onset.

All statistical analyses were performed using version 8.02 SAS software (SAS Institute, Inc., Cary, NC, USA). For this complementary analysis, quantitative variables were described by frequency, mean, standard deviation (SD), median and range, according to four (70-74, 75-79, 80-84, and 85+ years) and two (70-79 and 80+ years) age-groups, or to two groups defined by PHN (with or without) at months 3,6 , and 12 . The four age-groups have 
been defined based on the 85+ age-group (i.e., currently considered as the 'old old') in order to have a similar number of patients in each age-group. Results based on the two age-groups are disclosed only when they brought additional information to the comparison made on the four age-groups. Qualitative variables were described by frequency and percentage of each modality. Fisher, $\mathrm{Chi}^{2}$, or Wilcoxon tests were used to compare groups. Regression analysis for repeated measures was used to assess the impact of age on score evolution over time (day 0 and months 3, 6 and 12) and the influence of age on each parameter regardless of time.

\section{Results}

\section{Participants}

644 GPs enrolled in the ARIZONA study 1,517 patients aged 50 years and over, of whom 1,358 satisfied the inclusion criteria. Out of these 1,517 patients, 609 (45\%) were $70+$ and were included in the present complementary analysis: 383 patients $(62.9 \%)$ were between 70 and 79 years of age and $226(37.1 \%)$ were $80+$; respectively, 220 (36.1\%), 163 (26.8\%), 137 (22.5\%), and 89 patients (14.6\%) belonged to the $70-74,75-79,80-84$, and $85+$ age-groups.
Table 1 presents the main baseline characteristics of the elderly patients in each of the four age-groups. In all age-groups, there were more women than men. Comorbidity (mainly cardiovascular disease) was frequent in all age groups (>70\%).

\section{$\mathrm{HZ}$ characteristics at baseline}

Table 2 presents HZ characteristics at baseline. The time-interval between rash onset and $\mathrm{HZ}$ diagnosis was commonly $\leq 2$ days in all age-groups. Rash severity did not qualitatively or quantitatively increase with age after 70 years. Ophthalmic zoster location was more frequent in the most elderly patients although the difference between age-groups was not significant $(p=0.57)$ : the frequency of ophthalmic zoster ranged from $5.5 \%$ in the $70-74$ age-group to $9.0 \%$ in the $85+$ age-group.

HZ-related pain, whose onset always slightly preceded rash onset in all age-groups, was frequent at baseline (reported by about $80 \%$ of patients, $n=486$ ). It was of moderate intensity without difference between age-groups: mean NPSI score around 30 and mean worst pain ZBPI severity score around 5 in all age-groups (Table 2). Burning pain was the main descriptor (data not shown).

Table 1 Main baseline characteristics of patients $(70+)$ included in the ARIZONA study

\begin{tabular}{|c|c|c|c|c|c|}
\hline Age (years) & $70-74(\mathrm{~N}=220)$ & $75-79(\mathrm{~N}=163)$ & $80-84(\mathrm{~N}=137)$ & $85+(\mathrm{N}=89)$ & $p$-value \\
\hline Sex (female): \% & 60.9 & 61.3 & 61.0 & 76.1 & 0.062 \\
\hline BMI $\left(\mathrm{kg} / \mathrm{m}^{2}\right):$ mean (SD) & $26.6(4.8)$ & $26.6(4.6)$ & $24.9(4.0)$ & $25.4(4.4)$ & 0.001 \\
\hline Comorbidity: \% & 72.8 & 78.4 & 81.5 & 78.7 & 0.261 \\
\hline Cardiovascular disease & 63.3 & 73.2 & 80.9 & 78.6 & 0.008 \\
\hline Diabetes & 13.3 & 17.3 & 4.5 & 11.4 & 0.324 \\
\hline Cancer & 8.2 & 11.0 & 8.6 & 11.0 & 0.263 \\
\hline Chronic pulmonary disease & 10.1 & 12.6 & 10.9 & 14.3 & 0.801 \\
\hline Other chronic disease & 33.5 & 24.4 & 28.2 & 25.7 & 0.351 \\
\hline \multicolumn{6}{|l|}{ Previous history of VZV disease: \% } \\
\hline Known history of varicella & 51.1 & 48.1 & 41.6 & 45.5 & 0.642 \\
\hline Known history of Herpes zoster & 20.5 & 17.9 & 16.1 & 11.2 & \\
\hline If history of VZV disease: \% & & & & & 0.663 \\
\hline$\geq 12$ and $<24$ months & 9.3 & 10.3 & 4.5 & 0.0 & \\
\hline$>24$ months & 90.7 & 89.7 & 92.5 & 100.0 & \\
\hline Familial status: $\%$ & & & & & $<0.001$ \\
\hline Married or partner & 67.9 & 63.4 & 45.5 & 32.4 & \\
\hline Widowed & 21.2 & 26.1 & 43.0 & 59.5 & \\
\hline Divorced or separated & 6.2 & 7.0 & 5.0 & 2.7 & \\
\hline Single & 4.7 & 3.5 & 6.6 & 5.4 & \\
\hline Living conditions: $\%$ & & & & & $<0.001$ \\
\hline At home or with close relatives & 96.9 & 97.9 & 91.7 & 82.7 & \\
\hline In a community & 3.1 & 2.1 & 8.3 & 17.3 & \\
\hline
\end{tabular}

$B M I=$ body mass index; $S D=$ standard deviation; $V Z V$ = varicella zoster virus. 
Table 2 Main baseline characteristics of herpes zoster and herpes zoster-related pain in each age-group

\begin{tabular}{|c|c|c|c|c|c|}
\hline Age group (years) & $70-74(N=220)$ & $75-79(\mathrm{~N}=163)$ & $80-84(\mathrm{~N}=137)$ & $85+(N=89)$ & $p$-value \\
\hline $\begin{array}{l}\text { Time-interval between rash onset and } \\
\text { herpes zoster diagnosis: } \%\end{array}$ & & & & & 0.179 \\
\hline$\leq 1$ day & 46.3 & 34.6 & 41.9 & 37.9 & \\
\hline$>1$ and $\leq 2$ days & 22.7 & 22.2 & 24.3 & 31.0 & \\
\hline$>2$ and $\leq 3$ days & 14.8 & 16.0 & 14.0 & 16.1 & \\
\hline$>3$ days & 16.2 & 27.2 & 19.9 & 14.9 & \\
\hline Rash location: \% & & & & & 0.070 \\
\hline Cranial, cervical, facial, and/or ophthalmic & 15.0 & 16.6 & 19.0 & 28.1 & \\
\hline Thoracic, abdominal and/or sacrolumbar & 72.3 & 66.3 & 62.8 & 61.8 & \\
\hline Upper and/or lower limbs & 8.2 & 11.7 & 8.0 & 5.6 & \\
\hline $\begin{array}{l}\text { Other location and/or combination of } \\
\text { previous locations }\end{array}$ & 4.5 & 5.5 & 10.2 & 4.5 & \\
\hline Rash severity (quantitative assessment): \% & & & & & 0.775 \\
\hline Few vesicles & 43.9 & 38.9 & 43.5 & 41.2 & \\
\hline Many vesicles (extensive rash) & 56.1 & 61.1 & 56.5 & 58.8 & \\
\hline \multicolumn{6}{|l|}{ Rash severity (qualitative assessment): $\%$} \\
\hline Simple vesicles & 86.9 & 80.3 & 85.5 & 81.2 & 0.294 \\
\hline Haemorrhagic lesions & 7.9 & 6.4 & 7.6 & 12.9 & 0.328 \\
\hline Necrotic lesions & 3.7 & 12.1 & 6.1 & 4.7 & 0.650 \\
\hline Ophthalmic zoster & 5.5 & 8.0 & 8.8 & 9.0 & 0.574 \\
\hline $\begin{array}{l}\text { Time interval between pain and } \mathrm{HZ} \text { vesicles onset: } \\
\text { mean (SD) (days) }\end{array}$ & $-1.0(2.3)$ & $-0.9(2.5)$ & $-0.8(2.4)$ & $-0.7(2.1)$ & 0.639 \\
\hline NPSI*: mean (SD) & $32.7(18.5)$ & $29.9(21.6)$ & $31.1(18.5)$ & $33.3(18.0)$ & 0.407 \\
\hline ZBPIt: worst pain severity score, mean (SD) & $5.4(2.5)$ & $5.1(2.8)$ & $5.8(2.6)$ & $5.5(2.6)$ & 0.185 \\
\hline Medical treatment: yes (\%) & 97.7 & 98.2 & 100 & 98.9 & 0.337 \\
\hline Antiviral drug & 96.3 & 93.1 & 92.7 & 96.6 & 0.318 \\
\hline Analgesics & 85.6 & 86.3 & 88.3 & 86.4 & 0.907 \\
\hline
\end{tabular}

NPSI = Neuropathic Pain Symptom Inventory; $S D=$ Standard deviation; ZBPI = Zoster Brief Pain Inventory.

*NPSI score $>30$ indicates moderate pain.

tfrom 0 , no pain to 10 , maximal pain.

98.5\% of patients had at least one medical prescription, mainly antiviral drugs (94.7\%) and analgesics (86.5\%). The percentage of patients under treatment did not differ with age.

\section{Impact of $\mathrm{HZ}$ and $\mathrm{HZ}-$ related pain on daily life, $\mathrm{HRQ}$ oL,} and mood at baseline

Results are presented in Table 3. At baseline, HRQoL, and mood were impaired in all age-groups: mean ZBPI interference scores were around 3, mean SF-12 PCS and MCS scores were below 50, and mean HADS depression scores close to 8 .

No significant difference was found in mean ZBPI interference scores between the four age-groups $(p=0.582)$.

As regards HRQoL, SF-12 PCS scores decreased significantly with age $(\mathrm{p}<0.001)$, indicating greater $\mathrm{HRQ}$ L impairment in the most elderly patients. The low SF-12 PCS scores observed in the $85+$ age-group were mainly due to the scores of the 'physical functioning' and 'vitality' dimensions. No statistically significant difference in SF-12 MCS scores was observed between the four age groups $(\mathrm{p}=0.413)$.

As regards mood, HADS depression scores increased significantly with age $(\mathrm{p}<0.001)$, indicating greater mood impairment in the most elderly patients. No statistically significant differences in HADS anxiety scores were observed between the four age groups $(p=0.237)$.

Change in HZ-related pain, daily life, HRQoL, and mood from day 0 to month 12

Figure 1 presents the percentage of patients who reported HZ-related pain from day 0 to month 12 . Prevalence of HZ-related pain dramatically decreased between day 0 and month 3 in all age-groups: overall, 66 patients (14.3\%) had PHN at month 3. Prevalence of PHN slightly decreased from months 3 to 12 : 30 patients (7.6\%) had 
Table 3 Burden of herpes zoster and herpes zoster-related pain at baseline in each age-group

\begin{tabular}{|c|c|c|c|c|c|}
\hline Age group (years) & $70-74(\mathrm{~N}=220)$ & $75-79(N=163)$ & $80-84(\mathrm{~N}=137)$ & $\geq 85(\mathrm{~N}=89)$ & $p$-value \\
\hline \multicolumn{6}{|l|}{ ZBPI score: mean (SD) } \\
\hline Interference score* & $3.2(2.3)$ & $3.1(2.4)$ & $3.5(2.3)$ & $3.6(2.7)$ & 0.582 \\
\hline \multicolumn{6}{|l|}{ SF-12† } \\
\hline PCS score: mean (SD) & $42.7(8.9)$ & $41.8(9.4)$ & $37.9(10.0)$ & $34.2(8.9)$ & $<0.001$ \\
\hline Physical functioning & $57.9(35.3)$ & $53.8(34.9)$ & $40.7(34.2)$ & $26.6(33.6)$ & $<0.001$ \\
\hline Vitality & $36.6(25.7)$ & $33.5(23.0)$ & $28.8(23.5)$ & $25.4(23.0)$ & 0.004 \\
\hline MCS score: mean (SD) & $41.1(10.2)$ & $38.7(11.5)$ & $39.6(10.9)$ & $41.0(9.8)$ & 0.413 \\
\hline \multicolumn{6}{|l|}{ HADS: mean (SD) $)^{\ddagger}$} \\
\hline Depression score & $6.3(4.0)$ & $7.9(4.4)$ & $8.1(5.2)$ & $9.8(4.9)$ & 0.001 \\
\hline Anxiety score & $6.9(4.2)$ & $7.9(4.1)$ & $7.3(4.6)$ & $7.1(4.3)$ & 0.237 \\
\hline
\end{tabular}

HADS = Hospital Anxiety and Depression Scale; $M C S=$ Mental component summary; $P C S=$ Physical component summary; $S D=$ Standard deviation; $S F-12=12$-item Short-Form health survey; $Z B P I=$ Zoster Brief Pain Inventory.

*From 0 , no interference to 10 , maximal interference.

${ }^{\dagger} \mathrm{S}$ cores $<50$ indicates health-related quality of life (HRQoL)impairment.

${ }^{\ddagger}$ Scores $>8$ indicate probable anxiety or depression.

PHN at month 12. At months 3, 6 and 12, the percentage of patients with PHN was always higher in the $85+$ than in the other age-groups. However, no statistically significant difference was found between the four age-groups $(\mathrm{p}=0.58, \mathrm{p}=0.34$, and $\mathrm{p}=0.24$, respectively).

Figure 2 presents mean NPSI scores from day 0 to month 12 in each age-group in patients who reported HZ-related pain (day 0) or PHN (months 3, 6 and 12). Pain intensity assessed by NPSI decreased significantly between day 0 and month 3 , and then decreased slightly between months 3 and 12 in all age-groups except for the 85+ age-group at month 6 and the 80-84 age-group at month 12, leading to a statistically significant interaction between time and age $(\mathrm{p}=0.01)$.

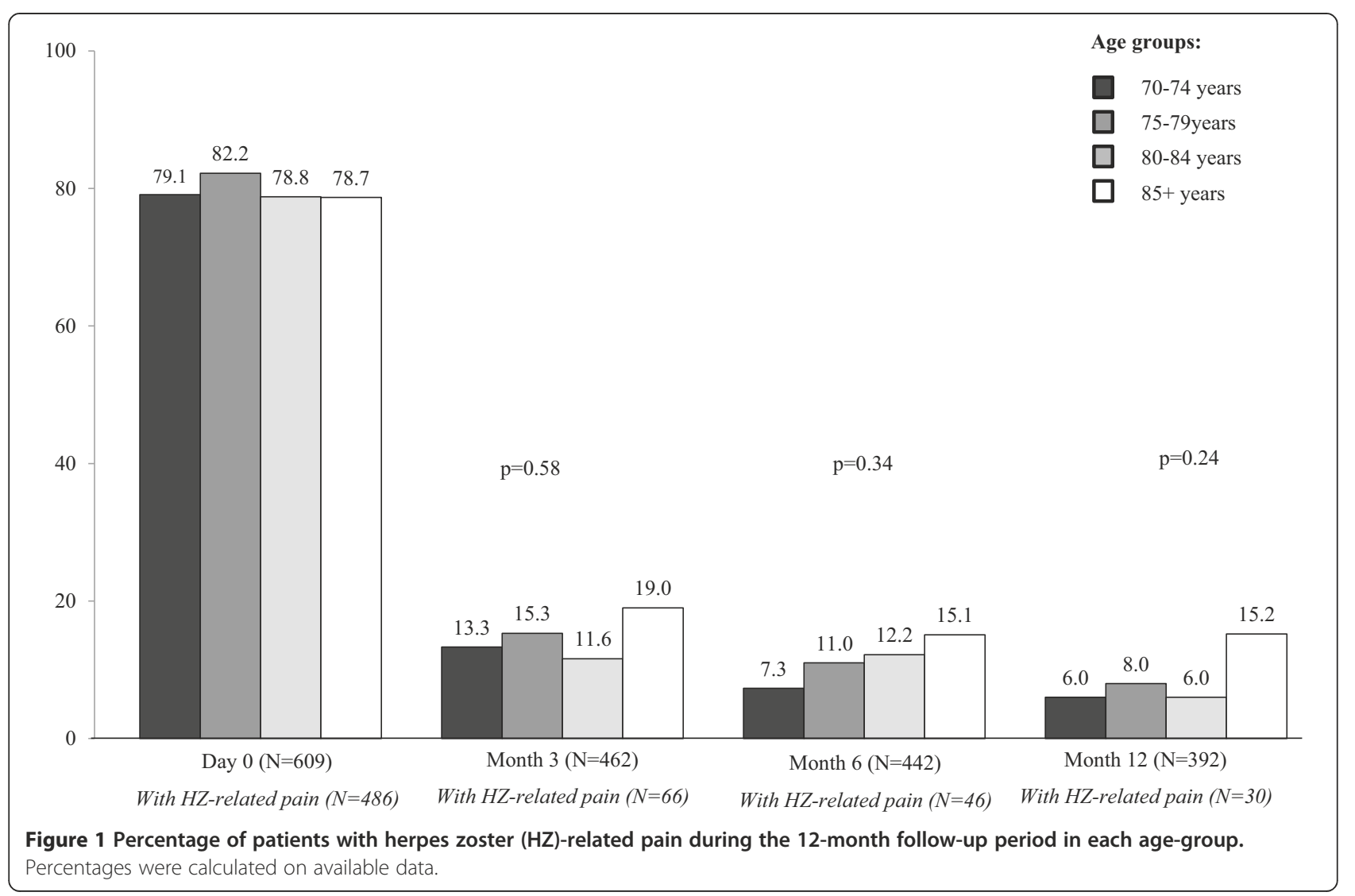




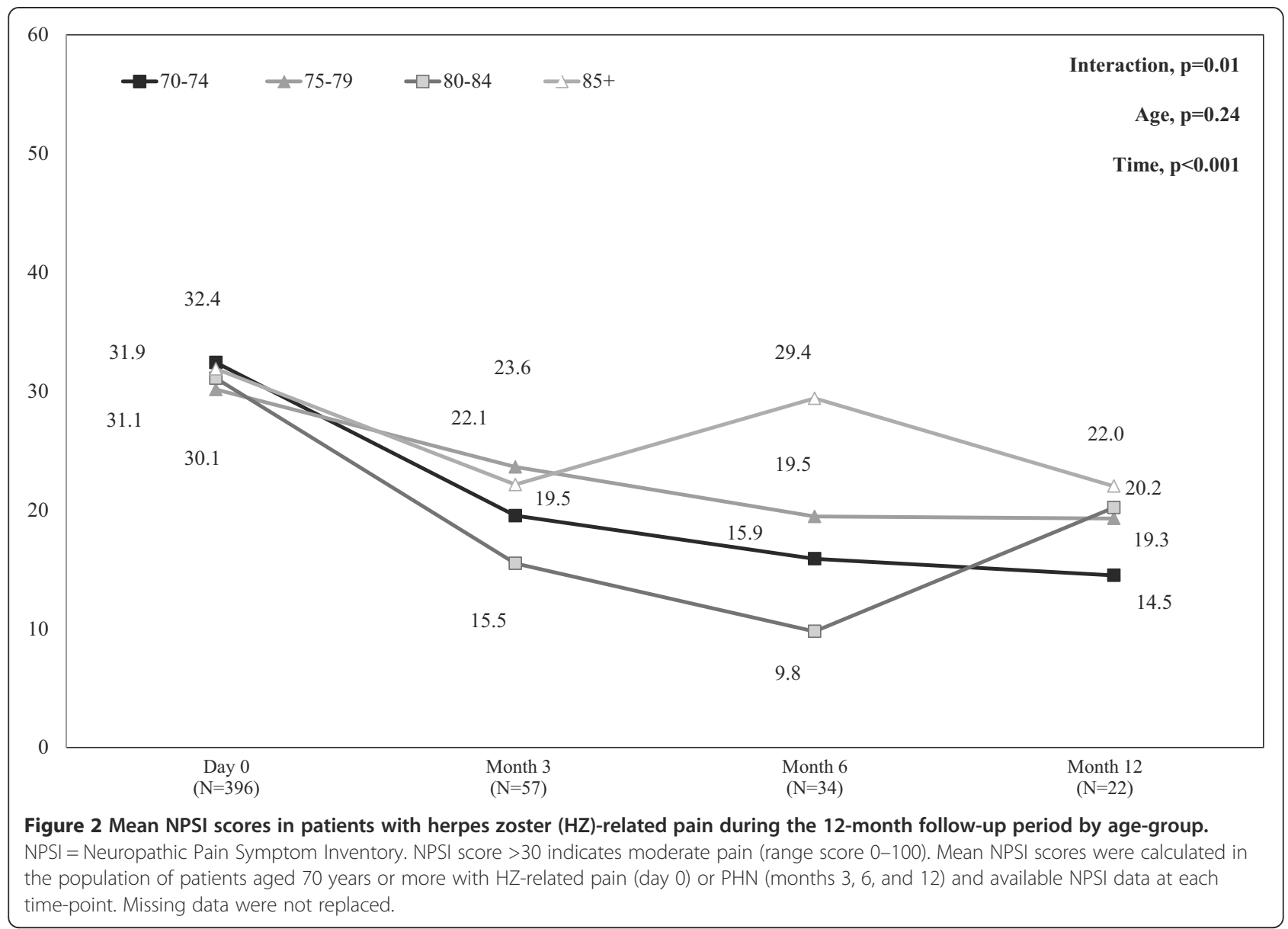

During follow-up, ZBPI interference scores in patients with HZ-related (day 0) or PHN (months 3 to 12) remained high (around 3), with no difference between age-groups (data not shown).

Figure 3 presents mean SF-12 PCS and MCS scores from day 0 to month 12 in each age-group. SF-12 PCS scores increased slightly, from day 0 to month 12 , in all age groups $(\mathrm{p}<0.001)$, indicating slight improvement in HRQoL. These results were always driven by the 'physical functioning' and 'vitality' scores (data not shown). In addition, at each time point, SF-12 PCS scores were lower in the $85+$ age-group than in the other agegroups $(\mathrm{p}<0.001)$, indicating greater HRQoL impairment in the most elderly patients. Comparison within the 85+ age-group found a significant difference in SF12 PCS scores between patients with and without PHN at month 3 (mean +/- SD: $27.0+/-11.26$ and $37.6+/-$ 12.26 , respectively; $\mathrm{p}=0.015$ ), but not at months 6 and $12(\mathrm{p}=0.956$, and $\mathrm{p}=0.919$, respectively $)$, indicating that impact of age and its comorbidities prevails over consequences of PHN. Regarding SF-12 MCS summary scores, from day 0 to month 12 , SF-12 MCS scores increased in all age-groups $(\mathrm{p}<0.001)$, indicating an improvement in HRQoL, without statistically significant difference in SF-12 MCS scores according to age $(\mathrm{p}=0.27)$.

Figure 4 presents mean HADS depression and anxiety scores from day 0 to month 12 in each age-group. HADS depression scores decreased from day 0 to month 12 , in all age-groups $(\mathrm{p}<0.001)$, indicating mood improvement. In addition, at each time point, HADS depression scores were greater in the $85+$ age-group than in the other age-groups $(\mathrm{p}<0.001)$, indicating greater mood impairment in the most elderly patients. Comparison within the $85+$ age-group found no significant difference in HADS depression scores between patients with and without PHN at months 3,6 , and $12(\mathrm{p}=0.52$, $\mathrm{p}=0.83$, and $\mathrm{p}=1.00$, respectively), indicating that the impact of age prevails over consequences of PHN. However, when patients were classified into two agegroups, in the 80+ age-group, HADS depression scores significantly differed between patients with and without PHN at months 3 and $12(\mathrm{p}=0.01$, and $\mathrm{p}=0.04$, respectively) but not at month $6(\mathrm{p}=0.30)$. HADS anxiety scores decreased from day 0 to month 12 , in all age-groups $(\mathrm{p}<0.001)$, indicating mood improvement, without statistically significant difference according to age $(\mathrm{p}=0.60)$. 


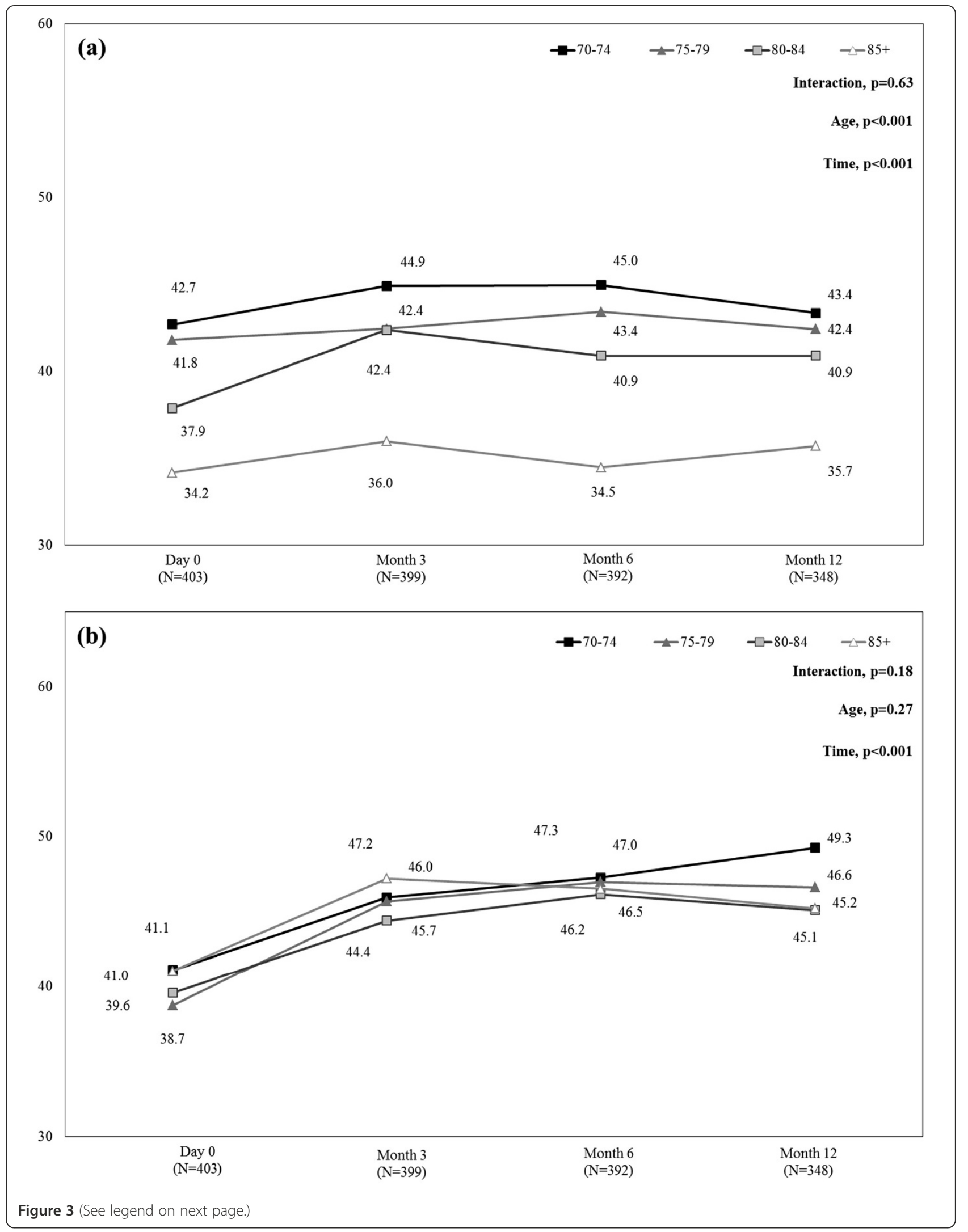




\section{Discussion}

In the ARIZONA study, which is to our knowledge the largest and longest prospective study to assess HZ burden in patients aged 50 years or more $(50+)$, it was previously shown that age $\geq 70$ years was a risk factor for both PHN and impaired HRQoL [16]. In a context of ageing of the older European population, the objectives of this post hoc analysis of the data collected during the ARIZONA study was to determine whether, beyond 70 years, age remained a risk factor for PHN and increased the burden of the disease, and whether a new age threshold could be defined in the most elderly patients.

\section{Frequency and severity of pain during the acute phase of $\mathrm{HZ}$ infection}

Older age has long been considered as a risk factor for severe pain during the acute phase of $\mathrm{HZ}$ infection [3]. In the entire ARIZONA cohort, we showed that at baseline the proportions of patients with extensive rash or haemorrhagic or necrotic lesions were higher in patients $70+$. By contrast, no difference between groups of patients was observed in the frequency or severity of HZrelated pain at inclusion [16]. In the MASTER study [23-25], older age also 'emerged as an independent predictor of greater severity-of-illness over 180 days, but not during the first 90 days after rash onset'. According to the authors, this result indicated that younger patients were as likely as older patients to experience considerable burden during the acute phase of $\mathrm{HZ}$, but had a lower risk of developing PHN and consequently experiencing lower severity-of-illness over the entire episode. The present results confirm that, in patients $70+$, the incidence of HZ-pain during the acute phase was large and similar in all age groups: regardless of age, approximately $80 \%$ of them reported HZ-related pain. Our data also indicate that there is no specific age cut-off after 70 years of age at which the frequency or intensity of pain during the acute phase of $\mathrm{HZ}$ infection is further increased. However, this analysis shows that the ophthalmic location of $\mathrm{HZ}$ infection tended to increase with age, from $5.5 \%$ in the $70+$ group to $9 \%$ in the $85+$ group.

\section{Frequency and severity of PHN}

Depending on the time-frame used in the literature, PHN occurs in $5 \%$ to more than $30 \%$ of patients [26]. Several possible risk-factors such as age, immunodepression, prodromal pain, and ophthalmic zoster have been considered [25]. PHN, defined as HZ-related pain persisting $\geq 3$ months, was reported by about $30 \%$ of $70+$ patients in an Icelandic study [27], 13\% of 70+ patients in the ARIZONA study, and $45 \%$ of patients in the MASTER study [23-25]. After one year, $15 \%$ of $70+$ patients in the Icelandic and $8 \%$ of the same age class in the ARIZONA study still had pain. The percentage of subjects with PHN was lower in the ARIZONA study than in the MASTER study. In the ARIZONA study [16], however, antiviral drugs were prescribed to $94.1 \%$ of patients for a median 7 days, which may have contributed to reduce the intensity of acute pain, accelerate vesicular rash healing and reduce acute-phase viral excretion duration [28]; conversely, in the MASTER study [23], only $26 \%$ of included patients received antiviral medication at the recommended dose and time. Although the efficacy of antiviral medication in PHN prevention is controversial [29], it may thus be hypothesised that early initiation of adequate treatment may have contributed to the lower prevalence of related pain at 3 months as compared with the MASTER study [23-25]. These findings nevertheless support the need for preventive vaccine strategies in elderly patients since more than 1 in 10 patients will develop PHN even with adequate treatment. Vaccination was shown to reduce the incidence of HZ and PHN and the HZ burden of illness (a composite end point sensitive to the incidence, severity and duration of $\mathrm{HZ}$ pain), to have a good safety profile $[17,30]$, and to be cost effective in elderly patients $[31,32]$. Centers of Disease Control and Prevention (CDC) recommended $\mathrm{HZ}$ vaccine for prevention of $\mathrm{HZ}$ and its complications among adults aged 60 years or more [33].

According to the literature, older age is an independent factor of PHN [3-7]. The ARIZONA study showed that older age $(70+)$ at baseline was an independent predictive factor for PHN [16]. Severity of HZ-related pain was comparable for $70+$ patients and younger, but the prevalence was significantly higher for $70+$ patients at months $1,3,6$, and 9 and close to significance at month 12. The present data showed that the percentage of patients with persistent HZ-related pain at months 3, 6 , and 12 was systematically but not statistically significantly higher in the most elderly patients (i.e. 85+).

Pain intensity appeared to remain constant in patients with persistent HZ-related pain (regardless of age). This additional result was partly consistent with that of the Canadian MASTER study, which found that mean pain 


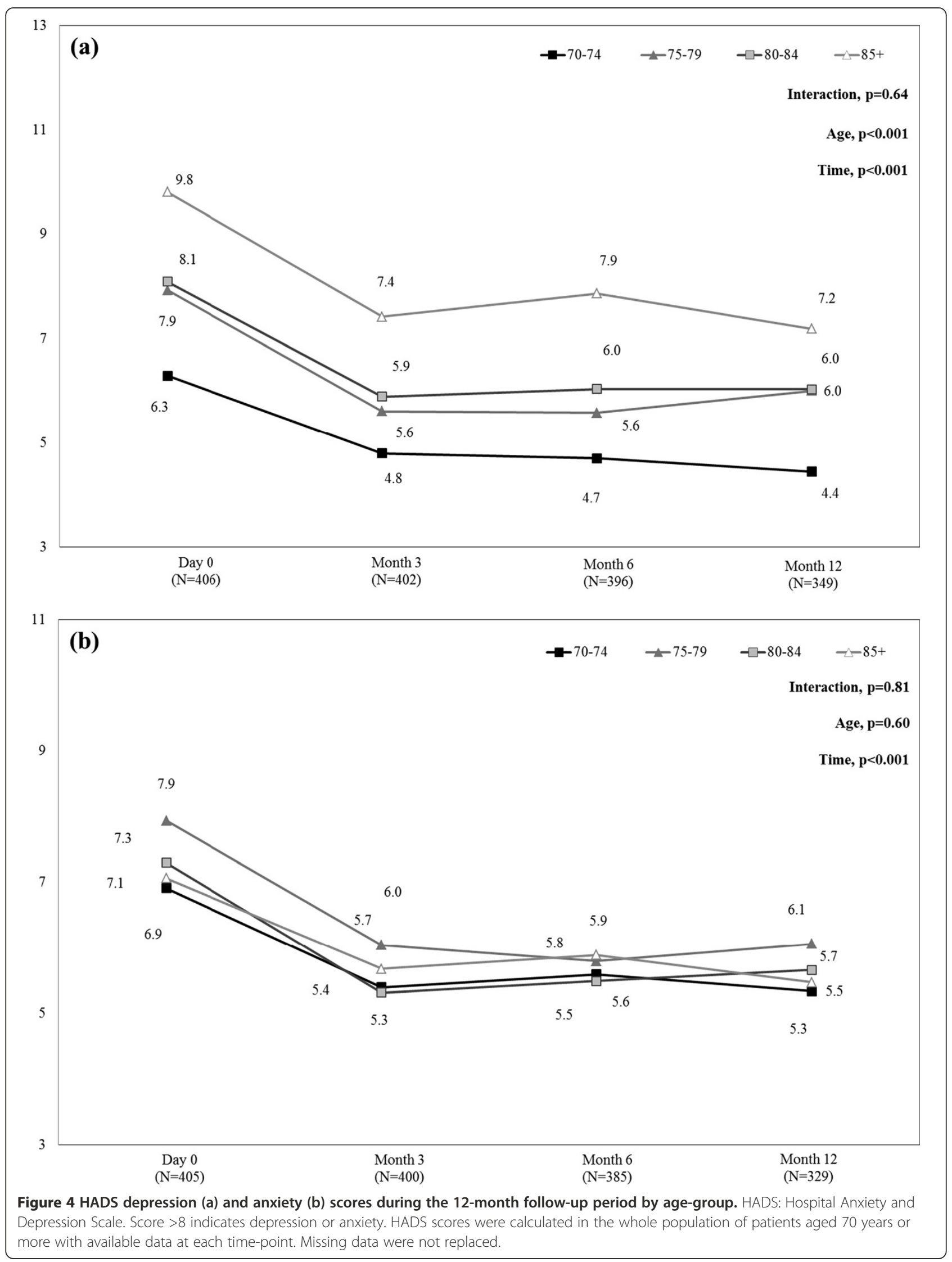


intensity decreased during the first month of the disease and then remained stable from months 1 to 6 [23]. In addition, no clear difference in the severity of PHN was observed according to age. This can possibly be partly explained by a negative influence of age on perceived degree of pain, as shown in acute myocardial ischemia as being a possible cause for delayed treatment in elderly patients, with a similar cut-off at 69 years [34].

\section{Disease burden}

It has been previously described that the PCS score of the SF-12 shows impairment with age, and that HZ infection severely impacts HRQoL [35,36]. In addition, it has been recently showed that an episode of $\mathrm{HZ}$ could lead to comorbidity decompensation and could jeopardize the health status of an older person with concomitant diabetes, COPD, or cardiovascular disease [37]. An impairment of HRQoL due to both age and PHN could thus be expected in the oldest patients in the ARIZONA study. In fact, only the physical component of HRQoL as assessed by the SF-12 PCS and depression as assessed by the HADS were impacted by age. Indeed, the difference over 8 points of baseline SF-12 PCS score between $85+$ and 70-74 age groups exceeds the minimal important difference of 3 points, by a meaningful [12].

This study showed that the older the patient, the lower the SF-12 PCS score and the higher the depression HADS score but failed to find clear difference in SF-12 PCS and HADS depression scores between patients with and without PHN at months 3,6 , and 12 . It may be thus suggested that the impairment of HRQoL was related more to age and its comorbidities than to the HZ infection per se.

However, the absence of significant difference can also be explained by some of the limitations in this our study. A selection bias cannot be ruled out as only data from patients who agreed to participate in the study were collected. However, the mean number of included patients per GP was consistent with the mean number of patients seen in general practice for $\mathrm{HZ}$ according to the French GPs Sentinelles network (https://websenti.u707.jussieu. $\mathrm{fr} /$ sentiweb/?page=presentation), indicating that almost all patients seen for HZ by a GP agreed to participate in the study. The second limitation is the small sample size and heterogeneity of the different age-groups (although as a whole, the sample size of ARIZONA cohort was large, with over 1,350 patients), which may not be sufficient to detect any effect. However, similar results were usually observed when patients were classified into two larger age-groups (70-79 and 80+). Finally, although the frailty risk increases with age, the population of $70+$ patients is probably highly heterogeneous: both well and frail patients with various chronic diseases are included in each age-group. That is why it is difficult to separate influence of $\mathrm{HZ}$ and age and chronic diseases. Further longitudinal studies with a large number of very old patients assessing chronological and physiological ages or frailty are thus needed to evaluate $\mathrm{HZ}$ and $\mathrm{PHN}$ burden in the $70+$. Indeed, beyond the age of 70 years, $\mathrm{HZ}$ and PHN can impair frail patients. In the model by Rockwood et al., frailty can be thought of as a dynamic balance between assets which help maintain a person's independence and deficits which threatens a person's self-sufficiency or functional capacity. In frail elderly, HZ and PHN can tip the balance in favour of the deficit [38].

\section{Conclusion}

There is no definite age threshold at which HZ severity, PHN frequency, pain intensity or disease burden as assessed by validated scales increased in patients aged 70 years or more. At population level, the cut-off of 70 years remains thus relevant for clinical and epidemiological studies. However, beyond the age of 70 years, $\mathrm{HZ}$ and PHN can impair frail patients. At individual level, assessment of the burden of HZ, HZ-related pain, and PHN on daily life, quality of life and mood in elderly patients appears necessary to improve their management and prevent functional decline.

\section{Abbreviations}

BMI: Body mass index; GP: General practitioner; HADS: Hospital Anxiety and Depression Scale; HRQoL: Health-related quality of life; HZ: Herpes zoster; MCS: Mental Component Summary (SF-12); NPSI: Neuropathic Pain Symptom Inventory; NS: Non-significant; PCS: Physical Component Summary (SF-12); PHN: Post-herpetic neuralgia; SD: Standard deviation; SF-12: Short-Form health survey; VZV: Varicella-zoster virus; ZBPI: Zoster Brief Pain Inventory.

\section{Competing interests}

GG, MP, CS and JG were members of'Avancees Vaccinales', a French vaccine expert group which was supported by an unrestricted grant from Sanofi Pasteur MSD, and which no longer exits. The ARIZONA study was supported by Sanofi Pasteur MSD.

\section{Authors' contributions}

JG, OC, DD participated in study design. DD supervised the study. MP, GG, $S E, J G, C S, D B$, and $O C$ participated in analysis and data interpretation. $M D$, MP, GG, JG, DB, OC drafted the manuscript. All authors participated in the critical revision of the manuscript. All authors read and approved the final manuscript.

\section{Acknowledgements}

The authors thank all the general practitioners that participated in the study. They are extremely grateful to the physicians Odile Launay (INSERM CIC BT505, Paris Descartes University and Cochin-Saint-Vincent de Paul Hospital, Paris, France), Claude Mann (Anaesthesia and Reanimation Department B, Saint-Eloi Hospital, Montpellier, France), Christian Rabaud (Infectious and Tropical Diseases Department, Brabois Hospital, Vandoeuvre-les-Nancy, France), Olivier Rogeaux (General Hospital, Chambéry, France), and Christophe Strady (Infectious and Tropical Diseases Department, Robert Debré Hospital, Reims, France) for their continued assistance in study design and data interpretation. The authors also thank Fabienne Péretz (fperetz@abelia-science.fr) for her assistance (supported by Sanofi Pasteur MSD) in preparing the manuscript.

\section{Author details}

'Paris-Diderot University Sorbonne Paris Cité, EA 7334 REMES,

Patient-Reported Outcomes Unit, 75010 Paris, France. ${ }^{2}$ Internal Medicine and Clinical Immunology Department, AP-HP, Bicêtre Hospital, 94275 Cedex Le 
Kremlin-Bicêtre, France. ${ }^{3}$ Department of Geriatrics, La Milétrie Hospital, University Hospital of Poitiers, 86000 Poitiers, France. ${ }^{4}$ Geriatric Medicine Department, A. Michallon North Hospital, University Hospital, 38700 La Tronche, France. ${ }^{5}$ Mapi, Real World Evidence, 69003 Lyon, France. ${ }^{6}$ Infectious Diseases Department, Annecy Regional Hospital, 74374 Pringy, France. 'Cabinet d'infectiologie, Clinique Saint André - Groupe Courlancy, 5 Boulevard de la paix, 51100 Reims, France. ${ }^{8}$ INSERM U987, Pain Evaluation and Treatment Centre, Ambroise Paré Hospital, 92100 Boulogne-Billancourt, France. ${ }^{9}$ Versailles Saint-Quentin en Yvelines University, 78000 Versailles, France. ${ }^{10}$ Clinical Research and Development Department, AP-HP, Saint-Louis Hospital, 75010 Paris, France.

Received: 18 May 2014 Accepted: 16 September 2014 Published: 1 October 2014

\section{References}

1. Hope-Simpson RE: The nature of herpes zoster: a long-term study and a new hypothesis. Proc R Soc Med 1965, 58:9-20.

2. Arvin A: Aging, immunity, and the varicella-zoster virus. N Engl J Med 2005, 352(22):2266-2267.

3. Schmader K, Gnann JW Jr, Watson CP: The epidemiological, clinical, and pathological rationale for the herpes zoster vaccine. J Infect Dis 2008, 197(suppl 2):S207-S215.

4. Dworkin RH, Johnson RW, Breuer J, Gnann JW, Levin MJ, Backonja M, Betts RF, Gershon AA, Haanpaa ML, McKendrick MW, Nurmikko TJ, Oaklander AL, Oxman MN, Pavan-Langston D, Petersen KL, Rowbotham MC, Schmader KE, Stacey BR, Tyring SK, van Wijck AJ, Wallace MS, Wassilew SW, Whitley RJ: Recommendations for the management of herpes zoster. Clin Infect Dis 2007, 44:S1-S6.

5. Yawn BP, Saddier P, Wollan PC, St Sauver JL, Kurland MJ, Sy LS: A population-based study of the incidence and complication rates of herpes zoster before zoster vaccine introduction. Mayo Clin Proc 2007, 82(11):1341-1349.

6. Gauthier A, Breuer J, Carrington D, Martin M, Rémy V: Epidemiology and cost of herpes zoster and post-herpetic neuralgia in the United Kingdom. Epidemiol Infect 2009, 137(1):38-47.

7. Stein AN, Britt H, Harrison C, Conway EL, Cunningham A, Macintyre CR: Herpes zoster burden of illness and health care resource utilization in the Australian population aged 50 years and older. Vaccine 2009, 27(4):520-529.

8. Katz J, Cooper EM, Walther RR, Sweeney EW, Dworkin RH: Acute pain in herpes zoster and its impact on health-related quality of life. Clin Infect Dis 2004, 39(3):342-348.

9. Coplan PM, Schmader K, Nikas A, Chan IS, Choo P, Levin MJ, Johnson G, Bauer M, Williams HM, Kaplan KM, Guess HA, Oxman MN: Development of a measure of the burden of pain due to herpes zoster and postherpetic neuralgia for prevention trials: adaptation of the brief pain inventory. J Pain 2004, 5(6):344-356.

10. Oster G, Harding G, Dukes E, Edelsberg J, Cleary PD: Pain, medication use, and health-related quality of life in older persons with postherpetic neuralgia: results from a population-based survey. J Pain 2005, 6(6):356-363.

11. Johnson RW, Bouhassira D, Kassianos G, Leplège A, Schmader KE, Weinke T: The impact of herpes zoster and post-herpetic neuralgia on quality-of-life. BMC Med 2010, 8:37.

12. Johnson RW: Herpes zoster and postherpetic neuralgia: a review of the effects of vaccination. Aging Clin Exp Res 2009, 21(3):236-243.

13. Weinke T, Edte S, Schmitt S, Lukas K: Impact of herpes zoster and post-herpetic neuralgia on patients' quality of life: a patient-reported outcomes survey. Z Gesundh Wiss 2010, 8(4):367-374.

14. Pickering $G$, Leplege A: Herpes zoster pain, postherpetic neuralgia, and quality of life in the elderly. Pain Pract 2010, 11(4):397-402.

15. Population Division, DESA, United Nations: World population ageing 1950-2050: executive summary. http://www.un.org/esa/population/ publications/worldageing19502050/pdf/62executivesummary_english.pdf.

16. Bouhassira D, Chassany O, Gaillat J, Hanslik T, Launay O, Mann C, Rabaud C, Rogeaux O, Strady C: Patient perspective on herpes zoster and its complications: an observational prospective study in patients aged over 50 years in general practice. Pain 2012, 153(2):342-349.

17. Oxman MN, Levin MJ, Johnson GR, Schmader KE, Straus SE, Gelb LD, Arbeit RD, Simberkoff MS, Gershon AA, Davis LE, Weinberg A,
Boardman KD, Williams HM, Zhang JH, Peduzzi PN, Beisel CE, Morrison VA, Guatelli JC, Brooks PA, Kauffman CA, Pachucki CT, Neuzil KM, Betts RF, Wright PF, Griffin MR, Brunell P, Soto NE, Marques AR, Keay SK, Goodman RP, et al: A vaccine to prevent herpes zoster and postherpetic neuralgia in older adults. N Engl J Med 2005, 352:2271-2284.

18. United Nations. Department of Economic and Social Affairs: Population Division: World Population Ageing 1950-2050. http://www.un.org/esa/ population/publications/worldageing19502050/.

19. Bouhassira D, Attal N, Fermanian J, Alchaar H, Gautron M, Masquelier E, Rostaing S, Lanteri-Minet M, Collin E, Grisart J, Boureau F: Development and validation of the Neuropathic Pain Symptom Inventory. Pain 2004, 108(3):248-257.

20. Schmader KE, Sloane R, Pieper C, Coplan PM, Nikas A, Saddier P, Chan IS, Choo P, Levin MJ, Johnson G, Williams HM, Oxman MN The impact of acute herpes zoster pain and discomfort on functional status and quality of life in older adults. Clin J Pain 2007, 23(6):490-496

21. Ware J Jr, Kosinski M, Keller SD: A 12-Item Short-Form Health Survey: construction of scales and preliminary tests of reliability and validity. Med Care 1996, 34(3):220-233.

22. Zigmond AS, Snaith RP: The hospital anxiety and depression scale. Acta Psychiatr Scand 1983, 67(6):361-370.

23. Drolet $M$, Brisson $M$, Levin MJ, Schmader KE, Oxman MN, Johnson RW Camden S, Mansi JA: A prospective study of the herpes zoster severity of illness. Clinical J Pain 2010, 26(8):656-666.

24. Drolet M, Brisson M, Schmader KE, Levin MJ, Johnson R, Oxman MN, Patrick D, Camden S, Mansi JA: The impact of herpes zoster and postherpetic neuralgia on health-related quality of life: a prospective study. Can Med Assoc J 2010, 182(16):1731-1736.

25. Drolet M, Brisson M, Schmader KE, Levin M, Johnson R, Oxman M, Patrick D, Blanchette C, Mansi JA: Predictors of postherpetic neuralgia among patients with herpes zoster: a prospective study. J Pain 2010, 11(11):1211-1221.

26. Kawai K, Gebremeskel BG, Acosta CJ: Systematic review of incidence and complications of herpes zoster: towards a global perspective. BMJ Open 2014, 4(6):e004833. 10.

27. Helgason S, Petursson G, Gudmundsson S, Sigurdsson JA: Prevalence of postherpetic neuralgia after a single episode of herpes zoster: prospective study with long term follow up. BMJ 2000, 321:1-4.

28. Li Q, Chen N, Yang J, Zhou M, Zhou D, Zhang Q, He L: Antiviral treatment for preventing postherpetic neuralgia. Cochrane Database Syst Rev 2009, 2, CD006866.

29. Bruxelle J, Pinchinat S: Effectiveness of antiviral treatment on acute phase of herpes zoster and development of post herpetic neuralgia: review of international publications. Med Mal Infect 2012, 42(2):53-58.

30. Morrison VA, Oxman MN, Levin MJ, Schmader KE, Guatelli JC, Betts RF, Gelb LD, Pachucki CT, Keay SK, Menzies B, Griffin MR, Kauffman CA, Marques AR, Toney JF, Simberkoff MS, Serrao R, Arbeit RD, Gnann JW, Greenberg RN, Holodniy M, Keitel WA, Yeh SS, Davis LE, Crawford GE, Neuzil KM, Johnson GR, Zhang JH, Harbecke R, Chan IS, Keller PM, et al: Safety of zoster vaccine in elderly adults following documented herpes zoster. J Infect Dis 2013, 208(4):559-563.

31. Szucs TD, Pfeil AM: A systematic review of the cost effectiveness of herpes zoster vaccination. Pharmacoeconomics 2013, 31(2):125-136.

32. Bresse $X$, Annemans $L$, Préaud E, Bloch $K$, Duru G, Gauthier A: Vaccination against herpes zoster and postherpetic neuralgia in France: a cost-effectiveness analysis. Expert Rev Pharmacoecon Outcomes Res 2013, 13(3):393-406.

33. Hales CM, Harpaz R, Ortega-Sanchez I, Bialek SR, Division of Viral Diseases, National Center for Immunization and Respiratory Diseases, CDC: Update on recommendations for use of herpes zoster vaccine. MMWR Morb Mortal Wkly Rep 2014, 63(33):729-731.

34. Rittger H, Rieber J, Breithardt OA, Dücker M, Schmidt M, Abbara S, Sinha AM, Jakob A, Nölker G, Brachmann J: Influence of age on pain perception in acute myocardial ischemia: a possible cause for delayed treatment in elderly patients. Intern J Cardiol 2011, 149:63-67.

35. Dorr DA, Jones SS, Burns L, Donnelly SM, Brunker CP, Wilcox A, Clayton PD: Use of health related, quality-of-life metrics to predict mortality and hospitalization in community-dwelling seniors. J Am Geriatr Soc 2006, 54:667-673. 
36. Frieling MA, Davis WR, Chiang G: The SF-36v2 and SF-12v2 health surveys in New Zealand: norms, scoring coefficients and cross country comparisons. Aust N Z Public Health 2013, 37(1):24-31.

37. Gil-Prieto R, San-Martin M, Alvaro-Meca A, Gonzalez-Lopez A, Gil de Miguel $A$ : Herpes zoster hospitalizations of patients with chronic illnesses in Spain 1998-2004. Vacunas 2011, 12:95-101.

38. Rockwood K, Fox RA, Stolee P, Robertson D, Beattie BL: Frailty in elderly people: an evolving concept. CMAJ 1994, 150:489-495.

doi:10.1186/1471-2334-14-529

Cite this article as: Duracinsky et al:: ARIZONA study: is the risk of post-

herpetic neuralgia and its burden increased in the most elderly

patients? BMC Infectious Diseases 2014 14:529.

\section{Submit your next manuscript to BioMed Central and take full advantage of:}

- Convenient online submission

- Thorough peer review

- No space constraints or color figure charges

- Immediate publication on acceptance

- Inclusion in PubMed, CAS, Scopus and Google Scholar

- Research which is freely available for redistribution 